\title{
Editorial
}

\section{Occupationally Acquired Infections: A Timely Reminder}

\author{
Charles W. Stratton, MD
}

Healthcare workers (HCWs). are known to be at risk for contracting an infection from a patient or from a patient specimen. ${ }^{1}$ It might be presumed that no one would be more aware of this risk than HCWs themselves; yet, these risks often are minimized or even ignored by HCWs who perhaps through long exposure to such risks have become immune to concern albeit not to infection. It is thus useful for HCWs to be reminded of these risks from time to time, so that we do not become too complacent. The January 2001 issue of Infection Control and Hospital Epidemiology begins the new year, and indeed the new millennium, with a timely reminder that occupationally acquired infections continue to be a very real risk for HCWs. This reminder is in the form of three reports that aptly illustrate the ongoing problems associated with such infections in HCWs. In this editorial, I will comment briefly on each of these reports, discuss the salient points, and suggest an approach that would avoid, or at least curtail, some of these problems in the future.

The first report, by Obasanjo et al, is entitled "An Outbreak of Scabies in a Teaching Hospital: Lessons Learned" and describes a large outbreak of scabies in an acute-care urban hospital. ${ }^{2}$ Overall, $773 \mathrm{HCWs}$ and 204 patients were exposed to an individual ( $\mathrm{HCW}$ or patient) with scabies and required prophylaxis or treatment. Of these, $113(15 \%)$ of $773 \mathrm{HCWs}$ and $82(40 \%)$ of 204 patients had symptoms or developed a rash consistent with scabies. This outbreak resulted in over $\$ 50,000$ in direct expenses and almost $\$ 20,000$ in person-hours lost due to sick leave. The effect of this outbreak on staff morale was far greater than its financial impact.

The second report, by D'Agata et al, is entitled "Nosocomial Transmission of Mycobacterium tuberculosis from an Extrapulmonary Site" and describes nosocomial transmission of tuberculosis from a genitourinary site. ${ }^{3}$ This elderly patient expired after 27 days of hospitalization during which a prostatic abscess was drained and bilateral orchiectomy was done. Disseminated tuberculosis was diagnosed at autopsy. There had been no evidence of active pulmonary tuberculosis during this patient's hospitalization, including negative acid-fast bacilli stains on bronchial washings done 5 days before his death. A total of $128 \mathrm{HCWs}$ were exposed to this patient during this hospitalization. Of 95 exposed $\mathrm{HCWs}$ who previously had nonreactive tuberculin skin tests, 12 (13\%) had newly positive tuberculin skin tests. The majority of conversions occurred among nurses, particularly those nurses who packed or irrigated the surgical wounds. Of note, all three autopsy personnel converted. In contrast, only 2 of 17 respiratory therapists exposed to this patient had conversion of their tuberculin skin test, suggesting that the transmission of tuberculosis from this patient did not come from the respiratory tract.

The third report is by Rice et al, entitled "An Evaluation of Hospital Special-Ventilation-Room Pressures," and assesses the magnitude and consistency of positive and negative airflow in hospital special-ventilation rooms. ${ }^{4} \mathrm{~A}$ total of 18 rooms were sampled, including 10 standard rooms (with no special ventilation), 4 airborne isolation rooms (with negative pressure), and 4 protective-environment rooms (with positive pressure). The results of this study showed that the pressure stability of these rooms varied by room and over time. Of the 274 pressure readings for airborne isolation rooms, $186(68 \%)$ of the readings showed compliance with the Centers for Disease Control and Prevention recommendations. At times, the positive pressure in protective-environment rooms dropped suddenly and dramatically; one such episode was due to a loose fan belt. The inconsistency of the ventilation control of the specialventilation-room pressures noted in this study suggests that these rooms would not have been reliably capable of achieving their stated purpose.

From the Department of Clinical Microbiology, Vanderbilt University School of Medicine, Nashville, Tennessee. Address reprint requests to Charles W. Stratton, MD, Associate Professor of Pathology, Director of Clinical Microbiology, Vanderbilt University School of Medicine, 4525 TVC, Nashville, TN 37232-5310.

00-ED-259. Stratton CW. Occupationally acquired infections: a timely reminder. Infect Control Hosp Epidemiol 2001;22:8-9. 
These three reports illustrate a number of important points about occupationally acquired infections. The first is that these infections are probably more common than most HCWs realize. There are several reasons for this. Occupationally acquired infections unfortunately often go undetected (eg, exposure to and infection by $M$ tuberculosis that goes undetected because tuberculin skin tests may not be done routinely on exposed $\mathrm{HCWs}$ ). These infections also may be underreported (eg, an HCW may contract scabies from a patient but not report it, because scabies may not be thought of as an infection). Finally, occupationally acquired infections are likely to be unappreciated even when reported (eg, occupational health services may see an $\mathrm{HCW}$ with a problem such as scabies and not fully appreciate the implications). Until there is a major problem such as seen with the scabies outbreak or the unexpected finding of disseminated tuberculosis on autopsy, occupationally acquired infections tend to be ignored or overlooked by HCWs and healthcare administrators alike.

The second point is that occupationally acquired infections have important economic consequences. If for no other reason, this fact should convince healthcare administrations to pay more attention to this problem. The third point is that there are systems problems as illustrated by the potential problems with special-ventilation-room pressures. Until there is an outbreak caused by an airborne pathogen such as $M$ tuberculosis that is inadequately contained by a suboptimal airborne isolation room, the problem with special-ventilation-room pressures is unlikely to be appreciated or, more importantly, fixed.

Having again been reminded that occupationally acquired infections continue to be a problem, is there anything that can be done to deal with this problem more effectively in the future? I believe that there is an important aspect of occupationally acquired infections that can be addressed: integration of occupational health services with the infection control program. As pointed out ${ }^{5}$ in Dr. Mayhall's text, Hospital Epidemiology and Infection Control, clear lines of communication need to be established between the occupational health services and the infection control department. This means that the director of occupational health services should be a member of the infection control committee. Moreover, infection control and occupational health services staff should communicate (email, telephone, fax, or memoranda) as necessary for integration of activities and assessment of mutual problems. Protocols for triage, evaluation, prophylaxis, and follow-up after exposures should be developed as a joint effort.

Within these protocols, the roles and responsibilities of occupational health services and infection control should be delineated clearly. Such integration of occupational health services with infection control has been done at Vanderbilt University Medical Center and works very well. I am sure that the three reports discussed in this editorial would stimulated a great deal of heated discussion at a joint meeting of occupational health services and infection control. Such meetings and discussions need to occur more frequently than they do now.

\section{REFERENCES}

1. Antony SJ, Stratton CW, Decker M. Prevention of occupationally acquired infections in posthospital healthcare workers. In: Mayhall CG, ed. Hospital Epidemiology and Infection Control. 2nd ed. Baltimore, MD: Williams \& Wilkins Co; 1999:1141-1158.

2. Obasanjo OO, Wu P, Conlon M, Karanfil LV, Pryor P, Moler G, et al. An outbreak of scabies in a teaching hospital: lessons learned. Infect Control Hosp Epidemiol 2001;22:13-18.

3. D'Agata EMC, Wise S, Stewart A, Lefkowitz LB Jr. Nosocomial transmission of Mycobacterium tuberculosis from an extrapulmonary site. Infect Control Hosp Epidemiol 2001;22:10-12.

4. Rice N, Streifel A, Vesley D. An evaluation of hospital special-ventilationroom pressures. Infect Control Hosp Epidemiol 2001;22:19-23.

5. Falk PS. Infection control and the employee health service. In: Mayhall $\mathrm{CG}$, ed. Hospital Epidemiology and Infection Control. 2nd ed. Baltimore, MD: Williams \& Wilkins Co; 1999:1381-1386. 